\title{
16. Resolving disputes over Aboriginal sacred sites: Some experiences in the 1990s
}

\section{Hal Wootten}

The material in this chapter arises out of some practical experiences of the way the Australian state has negotiated claims for the protection of Indigenous 'sacred' places that were threatened by private or public claims to exploit or remake the landscape in pursuit of wealth or public safety or amenity. For many readers this topic will bring to mind the unhappy experience of the Hindmarsh Bridge affair, where such a conflict dragged out through inquiries and litigation over some seven years and left behind bitter recrimination about the genuineness of Indigenous claims, the appropriateness of processes for evaluating them, and the proper role of experts such as anthropologists in those processes. ${ }^{l}$ It is unfortunate that this particular dispute is so dominant in public perceptions of such conflicts, and continues to frustrate the development of more appropriate procedures for their resolution, because it is not typical of the outcomes of Australian Government intervention, as my experiences will show.

In early April 1992 I was asked by the then Federal Minister for Aboriginal and Torres Strait Islander Affairs, Mr Tickner, to prepare a report for him in relation to an application by some Alice Springs Aboriginals seeking the protection, under the Aboriginal and Torres Strait Islander Heritage Protection Act, 1984, of some sites that would be destroyed by the construction of a dam, which the Northern Territory Government was planning in the Todd River above the town. For me it was to be the start of nearly a decade's involvement in 'the negotiation of the sacred' in a quite literal sense: the endeavour to find terms and conditions for resolving conflicts between Aboriginal claims for respect of the special significance that certain areas of land had for them, and claims to exploit those areas for private gain or public utility.

The first application referred to me arose out of a dispute between some Alice Springs Aboriginals, represented by the Central Land Council, and the Northern Territory Government, which was proposing to build a major dam for flood mitigation purposes on land that had particular significance for the Aboriginals, or, as was said in common parlance, contained sacred sites. The Territory Government claimed that a major benefit of the dam would be to save the lives of Aboriginals who might otherwise drown in the Todd River when a flood reached town. Undoubtedly some of the Alice Springs townspeople saw the dam 
as a potential site for water-based recreation, but the Territory Government strongly resisted the suggestion that it would be so used.

My report was to be the principal basis of the Minister's decision whether or not to protect the site, and under the legislation he could not act until he had received and considered my report. Because a lot of time had been used up in fruitless attempts to get an agreed settlement, the last interim declaration the Minister could make would expire in a little over a month, and the Northern Territory Government's bulldozers were ready to commence work immediately it expired. So I, a secular non-Aboriginal lawyer, had about a month to come to an understanding of the Act; the nature of the significance Aboriginals attached to land and, in particular, that Aboriginal women in Alice Springs attached to parts of the upper Todd River; the reasons why the NT Government had decided to build a flood mitigation dam at this particular place; and everything relevant to the Minister's weighing the desirability of the dam against the desirability of protecting the sites. There was no standing machinery for the implementation of the Act, and I made inquiries and wrote the report unassisted by any staff.

As it turned out, this was to be the first of four appointments as a rapporteur to the Minister. Later I dealt with challenges to BHP's mining of a site at Iron Knob in South Australia, to the recreational and pastoral use of Boobera Lagoon in northern NSW, and to some of the mining proposed in the Century Mine project in the Queensland Gulf. In each case my first task was to see if there was a possibility of an agreed solution that would relieve the Minister of the need to make an invidious decision, and then, if no settlement was possible, to collate the materials and considerations relevant to a wise decision. Mercifully in the other three cases I did not face such an acute time constraint as I did at Alice Springs.

That such conflicts involved the 'sacred' on one side at least is acknowledged in the common designation of such areas as 'sacred sites', although a community that seems willing enough to acknowledge the sacredness of sites at an abstract level may become sceptical of their genuineness when particular claims are advanced, or reluctant to concede that their protection should override the pursuit of wealth or projects conceived in the public interest. Recognition of the need to provide legal protection for Indigenous heritage came late to Australia, and initially was often conceived as underpinned by the requirements of archaeological and anthropological scholarship rather than by respect for Indigenous values, beliefs and feelings. In other words it was directed to the concerns of non-Aboriginal, rather than Aboriginal people, about the preservation of sites and relics. ${ }^{2}$

The Aboriginal and Torres Strait Islander Heritage Protection Act, 1984, was framed as a last resort measure, enabling Aboriginals to seek Commonwealth protection only if State or Territory law did not provide effective protection for 
a significant Aboriginal area, that is, 'an area of particular significance to Aboriginals in accordance with Aboriginal tradition'. This is the terminology of the Act, which does not use the word 'sacred'.

\section{Sacredness and significance}

The category of the 'sacred', and the items assigned to the category, are constructs of the culture that uses the term. One could not expect that it would translate with ready equivalence between cultures as different as the modern, capitalist, predominantly secular culture of mainstream Australia (which itself would contain many differences of interpretation), and the cultures of Aboriginal groups or individuals. ${ }^{3}$ Had the Aboriginal heritage legislation followed popular terminology and required decisions as to whether sites were 'sacred', it would have been very difficult to apply. However the problem has always been avoided. Although the early legislation did use the term 'sacred site', it defined it to mean 'a site that is sacred to Aboriginals or is otherwise of significance according to Aboriginal tradition'. ${ }^{4}$ The Aboriginal and Torres Strait Islander Heritage Protection Act, 1984 drops the word 'sacred' entirely, but retains the requirement that the particular significance arise out of 'Aboriginal tradition', which is defined to mean 'the body of traditions, observances, customs and beliefs of Aboriginals 5 generally or of a particular community or group of Aboriginals, and includes any such traditions, observances, customs or beliefs relating to particular persons, areas, objects or relationships'.

As a result there has been no need to debate whether sites are 'sacred', and the phrase 'particular significance', while susceptible to a number of different interpretations, has not, so far as I am aware, given rise to any difficulties. In my Boobera Lagoon report, for example, I noted that the phrase had been discussed by some members of the High Court in the Tasmanian Dam case (Commonwealth $v$ Tasmania (1983) 46 ALR 625), and went on to say that

the remarks of the judges support the view that 'particular' is directed only to the existence of a distinguishing characteristic, not to a particular level of significance.

In seeking a distinguishing characteristic, two possibilities have been pointed out. The area might have particular significance for Aboriginal people in contrast to its significance to other people, or it might have particular significance in contrast to the significance which all land or waters have for Aboriginals. On either view, it is clear that Boobera Lagoon has particular significance at least to the Aboriginal people associated with the Toomelah Boggabilla area. 


\section{Comparing the incommensurable}

Underlying my task in each case was the question: 'How does one measure the value of protecting an Aboriginal site against the value of some proposed activity that threatens it?' Or to put it crudely, 'How much is one prepared to pay to protect an Aboriginal site?' That in essence is what the Minister has to do at the end of the inquiry, unless an agreement can be brokered. There is invariably a price tag to protection, and the currency in which the price has to be paid varies - it may be money, perhaps in the form of lost GNP or revenue or export earnings; it may be in jobs or other opportunities foregone; it may be in the loss of the chance of water-based recreation for people living in a hot, dry climate, as in the Boobera Lagoon case, or it may be, as the Northern Territory Government was suggesting in my first assignment, in terms of lives that would be lost.

Of course it will not be the Minister, or the rapporteur who advises him, who will pay the direct price - they will not lose the profits or get drowned. The burden may fall on a private company, a government, individuals or some form of community interest. But the responsibility is the Minister's and there will usually be a political price to pay, and for both the Minister and rapporteur there may be other forms of unpleasantness. After the Alice Springs dam was stopped, I had to suffer the misrepresenting of my report and the traducing of my character under Parliamentary privilege by the Northern Territory Ministers of the day, with the Minister for Transport and Works saying, 'I tell Mr Tickner, Mr Wootten and the Leader of the Opposition that they will be hounded. Despite the fact that they will be long gone from the public arena, I will hound them next time there is a flood that causes damage or loss of life. Wherever they might be, whether it is in one year's time or 10 years time, I will ensure that they are reminded of this little charade, this shameful exercise, perpetrated on the people of the Northern Territory.' So far 12 years have passed uneventfully, and I sometimes wonder if I have the powers of the sacred sites to thank, but I still keep an eye on the Alice Springs weather reports.

I have not heard anyone advocate that all Aboriginal sites should be preserved intact, whatever the consequences, although I have encountered the view that sites should never be given special protection against lawful activities, because, it is argued, this would amount to racial discrimination. Once you put these extreme views aside, you become involved in a balancing of interests, a negotiation. Consistent with this, the Act requires the report to deal on the one hand with the particular significance of the area to Aboriginals and the nature and extent of the threat to it, and on the other hand with the effect of protection on the proprietary or pecuniary interests of other persons.

How do you balance one against the other? A philosopher might say that the conflicting interests are of such radically different kinds that one cannot weigh 
one against the other; they are simply incommensurable. However lawyers, and others responsible for bringing disputes to an end, learn to be pragmatic. In a recent paper to the Academy of the Humanities, I compared the pursuit of truth by historians and by courts. Historians have the luxury of dealing in provisional truth. They never have to make a final decision, they can decline to make a decision at all. Courts necessarily have a quite different approach, which is not to pursue truth for its own sake, but to respect it as one factor among a number in their task of putting an end to disputes as justly as possible. In essence a court does not and cannot say to parties 'These findings are the truth about your dispute'. It can only say, 'This is the closest we can get to the truth following a just and practicable procedure and with the time and resources available. We hope we got it right, but whether it's right or wrong, it is the basis on which you have to conduct your affairs for the future. Stop arguing and get on with life.'6

It is the same with the protection of a site. The competing interests may be incommensurable, but a decision has to be made or the bulldozers will roll. A failure to make a decision amounts to a decision that the site will not be protected.

How then does one go about weighing the contesting claims? The conflicting interests may be logically incommensurable, but reasonable people make choices between incommensurable things every day. Popular wisdom says that apples and oranges are not commensurable, but few people would have difficulty in choosing between ten apples and one orange, or between a good apple and a bad orange, or an apple worth a dollar and an orange worth a cent, and a dietician may give you other information that facilitates a choice.

This example illustrates two points. One is that finding out more about the objects of comparison may make choice easier, although it won't necessarily do so. The other is that you may be able to find criteria by which very different things can be compared. In our capitalist society money is often invoked to play this role. Market economists, for example, tend to think that everything can be given a monetary value. I once heard an economist making a case for nuclear power add in so many hundred thousand dollars for each life that would be lost, assuring his audience that he had an actuarial basis for what he was doing. And I believe the Australian Bureau of Agriculture and Resource Economics has calculated that it would be cheaper to move the inhabitants of low-lying Pacific Islands to Australia than cut the consumption of greenhouse gas producing fossil fuels. I have not seen an attempt to put a money value on a sacred site, although questions sometimes arise as to whether Aboriginals will accept monetary compensation for interference with a site, and opposing interests are quick to argue that willingness to accept financial compensation would show that the claim of significance is not bona fide. 


\section{The role of the rapporteur}

So what does a rapporteur do? I preface my answer with the observation that in exercising any legal power or function under Australian law, one is constrained by some basic features of our legal system. We are a community that accepts the rule of law. Any exercise of power must find its authority in the law, and be carried out within the limits of the conferred power and in accordance with any conditions or requirements attached to it. A power or function is conferred for a particular purpose, which is either expressly stated in the law or inferred from the nature of the law, and it can't be used for any other purpose. In exercising the power, all relevant factors, and no irrelevant factors, must be taken into account. Again, what factors are relevant may be expressly stated in the law, or inferred from its purpose.

A power to make a decision that may adversely affect someone's interests must also be exercised in accordance with the principles of natural justice, unless legislation otherwise provides. This means particularly that the person exercising the power should not be biased, or reasonably open to the suspicion of bias, and should give a fair hearing to anyone whose rights may be affected.

The role of the rapporteur is thus a quasi-judicial one; he or she must be independent and give a fair hearing to all interests affected and report fairly to the Minister, not omitting anything that is relevant to be taken into account, or giving weight to anything that is not relevant. The functions of the Minister and the rapporteur are thus confined within a procedural mould and cannot be exercised arbitrarily.

As a rapporteur I had to subject both sides of the balance to scrutiny and evaluation. Scrutinising and evaluating Aboriginal beliefs is an invidious task, particularly for a non-Aboriginal person. It is not surprising that people-any people - would resent having what are essentially religious beliefs scrutinised, particularly by someone who does not share those beliefs, or even the cultural framework within which they exist. It is not surprising that women may be reluctant to have their beliefs, especially gender-restricted beliefs, evaluated by a man. And it is certainly to be expected that many Aboriginals may resent having their beliefs evaluated by members of the dominant community that dispossessed them. These conflicts were among issues considered by Elizabeth Evatt when she was appointed to review the Act in 1995, and she made recommendations designed to mitigate or eliminate them, which the present Government has not adopted. ${ }^{7}$

For my part, I simply had to live with these problems, and do what I could to minimise their effects. Over and above the resentment of intrusion on their privacy and the inner sanctum of belief that might be felt by anyone whose beliefs are subjected to scrutiny, I have observed three specific things causing hurt or anger to Aboriginal people in these applications. One is scepticism of 
their veracity or bona fides, another is the ridiculing of their beliefs (a deplorable feature of the Coronation Hill dispute), and a third is the presumption of arguing that a belief is in some sense 'disproved' by showing that people have flouted it without incurring adverse consequences. It must be particularly galling to Aboriginals that these hurts are so frequently offered by the most ignorant and bigoted of white Australians, who are secure in a sense of their own intellectual superiority that is not obvious to anyone but themselves.

In coming to grips with the Aboriginal claim, a rapporteur will usually have the benefit of at least one anthropological report as well as direct input from Aboriginal people themselves. Sometimes a report may be obtained by one or more interested parties and then offered adversarially to the rapporteur. In less contentious cases there may be agreement on retaining a particular anthropologist to report. Sometimes there is complaint that anthropologists should not be used, but competent anthropologists are of enormous value. Their professional knowledge enables them to provide a context for the claim, and to cast light on its plausibility and its significance. In addition their linguistic and fieldwork skills enable them to collate evidence from Aboriginals that would take an inordinate time for the rapporteur to collect, if indeed it were possible. Sometimes the anthropologist may have worked in the relevant community for a long time.

\section{The Alice Springs Dam Case}

In the Alice Springs Dam case I found that there was undisputed and long authenticated evidence of the beliefs in question. The sites in question derived their significance from two Dreaming tracks that converged in the area. One was the path of Two Women whose mythical journey started far to the southwest in Pitjantjatjara country, the other the path of a group of Uncircumcised Boys who travelled from the area of Port Augusta to the north coast of Australia. Women from distant lands and tribal groups who shared the Two Sisters story had on several occasions travelled to Alice Springs to support the claim of the Arrernte women, who put their views forcibly to me in a large meeting from which all other men were excluded. They confided to me, for transmission to the Minister, 'secret women's business' that would normally never be disclosed to men.

With the co-operation of the Northern Territory Solicitor-General, who represented the Territory Government, and acted throughout with the utmost professionalism and good sense, arrangements were worked out for handling the 'secret women's business'. It was agreed that it could be revealed to the Minister and myself, as the women had volunteered, and supplied to the Northern Territory Government on the basis that the details would be confidential to a female anthropologist employed by the Government. Fortunately in the Territory the parties were accustomed to devising ways of dealing with confidential 
material in land claims, and one of the problems on which the Hindmarsh Bridge application later foundered was thus avoided.

Investigating the claim was a novel and moving experience for me. I recorded some of the problems I wrestled with in the following section of the report, which was frequently quoted from during the subsequent Hindmarsh Bridge disputation:

7.1.9 To reveal these beliefs to anyone not entitled to know them under Aboriginal tradition (including other Aboriginals and even people of the opposite sex in the same community) is itself a kind of desecration, and it has been done reluctantly and painfully on the basis that it is necessary to prevent the destruction of important sites. I feel a personal obligation to respect the confidentiality of the information given to me. Moreover, I would not wish my report to be the vehicle for the public trivialisation and ridicule of Aboriginal beliefs in the media by uncomprehending people, a situation which was such a shocking feature of the debate over Coronation Hill.

7.1.10 It is difficult for those of us who have grown up in Western European culture to appreciate the nature of the attachment to and concerns about such areas on the part of Aboriginals. Our perceptions of values which we categorise as spiritual, religious, sacred, traditional, and political are shaped by our own culture and do not necessarily fit with categories or with concerns in Aboriginal culture. This is exemplified by the absence from the English language of any word corresponding to what we unhappily translate as 'the Dreaming'. The anthropologist's report in this case stresses, for example, that our division between sacred and secular realms does not correspond to traditional Aboriginal ideas. The Western notion of knowledge as objective and scientifically based does not square with the Aboriginal notion of knowledge, which in the fields with which we are concerned, derives from authoritative statement by a person who, in terms of traditional authority, was qualified to define the knowledge.

7.1.11 Western civilisations have long been accustomed to the notion of traditions as being recorded and authenticated in written texts, and more recently to their being interpreted and their correctness tested in a rationalist manner in the light of the results of historical and scientific inquiry. It is not easy for those who have grown up and been formally and informally educated in this culture to understand and empathise with traditions communicated by oral narrative, song, art and dance, and having an authority quite independent of historical, scientific and rationalist scrutiny. 
7.1.12 One way in which Aboriginals stress the importance of sites in the area is by voicing the belief that destruction of the sites would lead to devastating social consequences and particularly consequences to all women, including non-Aboriginal women, and to relations between the sexes. While I refer to this as an indication of the degree of importance attached by Aboriginals to the sites, I warn against the tendency of Europeans to trivialise Aboriginal beliefs by treating such fear of consequences as their essence.

7.1.13 I can assure the curious that the confidentiality is not because the information would be found titillating, shocking or even particularly interesting by Western standards. It simply lacks significance in Western culture, and I could not claim to appreciate its significance to Aboriginals. The issue should not be whether, judged by the norms and values of our secular culture or our religions, the sites are important, but whether they are important to Aboriginals in terms of the norms and values of their traditional culture and beliefs. In other words the issue is not whether we can understand and share the Aboriginal beliefs, but whether, knowing they are genuinely held, we can therefore respect them.

It became clear to me that there were strongly and widely held beliefs that would be severely affronted by interference with the sites, that a significant number of women would suffer great anxiety because they believed that apocalyptic consequences would follow, and that many Aboriginals saw the matter as a test case of white Australia's respect. But should this prevail against the building of a dam that would not only protect the town from flood damage, but save lives of people who might otherwise be drowned in floods, as a number of Aboriginals had been in the past?

I found the issue easier to resolve than I had feared. It is not possible to go into the matter fully here, but a detailed examination of the dam proposal showed that by normal engineering standards the dam was uneconomic, returning over its life less than 33 cents in material terms for every dollar spent, and that there were other ways of reducing flood damage to the town. The case for the dam therefore rested heavily on its potential for saving lives. However investigation showed that there had been seven drownings in 20 years, and most of these, probably all, could have been prevented by relatively simple steps that could be implemented in the future. I asked rhetorically whether anyone who had \$20 million to spend on saving Aboriginal lives would use it on building this dam. On receipt of my report the Federal Minister prohibited the building of the dam.

\section{Mining at Iron Knob}

The next matter referred to me involved a claim to protect an area from mining at BHP's mine at Iron Knob in South Australia, a step that would sterilise millions 
of dollars worth of iron ore. The Aboriginal people in the area had lived an urbanised life for some time, and when the elderly Aboriginal woman who had instigated the claim died, there was no local person who could speak authoritatively to it. With financial assistance from BHP, which acted throughout in a very sympathetic and co-operative fashion, senior traditional Aboriginal men and women from other tribes far to the north were brought to Iron Knob. Although they had never visited the area before, they knew of the country in detail through songs and dances that recorded the stories attached to a Dreaming track that passed through Iron Knob on the way to their own country. They were immediately able to recognise and explain the mythical significance of the various features of the landscape.

For reasons that are too complex to go into here, this case would have presented me with a difficult balance to draw up, but the matter took a surprising twist. The BHP manager became committed to the importance of preserving Aboriginal culture, offering money for books, films, dancing companies, and visits by local to more traditional peoples. The Aboriginal people were grateful and impressed, but still unable to agree to the destruction of the site. The impasse was broken when the manager offered to dig up the sacred site and install it on land the company would provide for a cultural centre at Whyalla. I expected this proposal to get no support, as the actual location of the site seemed critical to its significance, but to my surprise the proposal was immediately embraced by the leading Aboriginal spokeswoman, and a deal was done. Some of the men, however, seemed uneasy, and I was not unduly surprised to learn a few years later that the Aboriginals had regretted their decision and persuaded the company to leave the site undisturbed.

\section{Boobera Lagoon}

In May 1995 I was appointed rapporteur in relation to Boobera Lagoon, an old path of the MacIntyre River in New South Wales near the Queensland border. According to the mythology of the local Aboriginal people, the Lagoon was made by and is now the resting place of a local version of the Rainbow Serpent, a being that appears in Aboriginal mythology in many places. There was no doubt about the genuineness of the claim, which had long been documented by anthropologists and consistently pursued by local Aboriginals whenever an opportunity had arisen over the years. The most acute among many issues was that the Lagoon had become a major waterskiing site, providing the only water-based recreation for the inhabitants of the hot, dry, dusty Goondiwindi area, but one that the Aboriginals found offensive and disrespectful to what they treasured as a sacred place. Also at issue was the effect of cattle depastured around the Lagoon, most acutely where a Travelling Stock Route bordered the Lagoon. Apart from spiritual desecration, the Aboriginals were concerned that 
both the waterskiing and the cattle were causing serious environmental damage to the Lagoon.

The matter proved difficult. The Aboriginals had been fighting for the protection of the Lagoon for many years, and although they were quite happy to share its enjoyment with non-Aboriginals who treated it respectfully, they would not condone waterskiing or continued environmental damage. The non-Aboriginal side was no less intransigent. The local authority managing the Travelling Stock Route would not even agree to watering cattle with water pumped into troughs from the Lagoon, a procedure that would have allowed its bank to be fenced off. One could not but feel sympathy for the water-skiers who had been using the Lagoon for many years and had come to regard it as a major feature of family and community recreation for which no substitute was available. There are many aspects canvassed in my report in the course of weighing up the competing claims, but in the end I recommended that waterskiing be banned and arrangements made to keep travelling stock off the Lagoon bank.

The recommendation was to have a chequered history. My report had been commissioned by the Labor Minister, Robert Tickner, but by the time I presented it in August 1995 the Government had changed and Senator Herron, a Queensland Liberal, was the Minister. Although I believed that my report made a persuasive case for banning the waterskiing and taking other steps to protect the Lagoon, I held out little hope of a positive outcome, particularly given that the move was opposed by the Deputy Prime Minister who held the adjoining Federal seat. ${ }^{8}$ Several years passed with no decision announced, although I did hear a report of a white-headed man in a Commonwealth car calling in at Boggabilla Hotel to seek directions to Boobera Lagoon. Then under Ministerial rearrangements the Aboriginal Heritage Section was transferred on 17 December 1998 to the Department of the Environment, and Mr Herron, I am told, breathed a sigh of relief. However the Prime Minister decreed that he must deal with the matter before handing it over. To everyone's surprise he banned the waterskiing, softening the blow with a grant of $\$ 5$ million to construct a new waterskiing site near Goondiwindi. There were a number of postponements, but ultimately the new site was constructed and quiet descended on the Lagoon. It is a declared Aboriginal place under NSW law, and is now managed by a committee with a majority of Aboriginal members. They are gradually negotiating increased protection from cattle damage around the lagoon, and on recent inquiry I was told that the only blight on their satisfaction was that the $\$ 5$ million to build the new waterskiing site was taken out of Aboriginal Heritage Protection Funds.

\section{Mining in 'blackfella country'}

About the Century Mine negotiations, there is little to say. The Carpentaria Land Council made an application under the Act for the protection of some sites within the proposed mining lease, but there was never a real problem. The Company 
was determined that sites would not become an issue and was willing to make whatever concessions were necessary on that score, as well as anxious to lay the foundations for the future operation of the mine in a way that would bring real benefits to the local communities. The parent company was Applera Corp-Celera Genomics Group (CRA), and one sensed that the disastrous experience of Bougainville Copper was never far from the minds of its executives. Many matters were negotiated, but I believe the real underlying issue was that many Aboriginals, including Murrandoo Yanner, the influential Director of the Carpentaria Land Council, still saw and treasured the Gulf as essentially 'blackfella country', and did not want its character changed by the intrusion of a major mine. The issue was summed up for me by an incident at a Darwin seminar when Tracker Tilmouth, the very able and entrepreneurial Director of the Central Land Council, was waxing lyrical about the successful enterprises of the Council and the opportunities available in business partnerships. When he finished, Murrandoo stood up and asked, 'Well Tracker, they are all fine things, but when do you get time to be a blackfella?'

That seems to me the dilemma that every Aboriginal faces. How do you remain a blackfella while engaging with what the modern world has to offer? What are you prepared to forgo to hang on to the things that you find essential to your identity? To the extent that I am a bleeding heart, my heart bleeds for the individual Aboriginals who every day have to make painful decisions and compromises in the course of finding a satisfying and dignified place in an alien society that took over their country, long excluded them from participation, but today impatiently expects them to accept whatever place is offered them or rapidly find their own.

\section{Some reflections}

One thing that I found striking in all the applications with which I dealt was the peaceful and law-abiding way in which Aboriginals pressed their claims, and their capacity to be understanding of their opponents. The only occasion in which the question of violence was raised was in relation to Boobera Lagoon. As I described in my report, the Aboriginals of the area had a long history of pressing their claims lawfully and constructively whenever the opportunity arose, and no one could have credibly predicted violence on their part. It was white residents who predicted that if a declaration were made prohibiting water-skiing, water-skiers would resort to violence and defy it, and that the white community would also react vindictively against Aboriginals, for example by refusing them employment. Two members of Parliament hinted at the same thing when, in opposing protection, they expressed their fear that it might 'lead to a worsening of the already fragile relations'. The supposition in all these submissions was that the threat of white violence was a reason for refusing the 
Aboriginal claim, a view that I rejected, although I did recommend a strategy of community public relations to head it off. ${ }^{9}$

The reaction of the Aboriginal community was stoic. The submission on their behalf read:

Any racial violence which flows from the granting of the declarations will merely be a continuation of what they have had to tolerate since the beginning of European occupation. Concern about the possibility of racial violence should not sway the Minister away from making the declarations. To do so would be a grave injustice to Aboriginal people. It would be a continuation of what is already perceived to be a flawed system biased against Aboriginal people. It would be the law succumbing to intimidation from those prepared to threaten violence by the use of illegitimate force to obtain their ends.

This was a view with which I agreed, and one that in my view the state must be prepared to stand up for in negotiating the sacred in a multicultural community.

The Australian state on whose behalf I was acting is essentially secular. Although its Constitution was expressly adopted in humble reliance on the blessing of Almighty God, it gave no powers or privileges to God or God's representatives or adherents and expressly forbade the Commonwealth from establishing any religion, imposing any religious observance, prohibiting the free exercise of any religion, or requiring any religious test for any Commonwealth office or public trust. As it happens, my personal outlook is secular, although I hope respectful and understanding of other views, but even if I had not been, it would have been my duty to act in a manner becoming the secular agent of a secular state. From this secular viewpoint, the beliefs of Aboriginal claimants, whether sacred in character or not, were not something to be judged as right or wrong, or as better or worse, or more or less credible, than other beliefs, but something to be respected, not merely as an expression of their liberal right to different views, but as part of their human identity. It may well be that it is easier for a secular state to negotiate the sacred, than it would be for one committed to a particular view of the sacred as the official and correct one.

\section{ENDNOTES}

1 An independent scholarly account of the events remains to be written. A factual summary can be found at the beginning of the judgment of Justice von Doussa of the Federal Court in Chapman v Luminis Pty Ltd, 21 August 2001, which ended the litigation. As to the resultant consideration of law reform, see endnote 4.

2 For example, in the Northern Territory the Native and Historical Objects and Areas Preservation Ordinance 1955 was enacted to protect 'prescribed objects'. A prescribed object was defined as 'an object relating to the Aboriginal natives of Australia which is of ethnological or anthropological interest or value' (s. 3). Six years later the Ordinance was amended to prohibit interference with 'any place used by Australian Aboriginal natives as a ceremonial, burial, or initiation ground' (s. 9H). Another 17 years 
went by before there was an attempt in the Territory to give general legislative protection to sites of significance according to Aboriginal tradition (Aboriginal Sacred Sites Ordinance 1978). The first legislation in Western Australia vested control of sites in the Western Australian Museum (Aboriginal Heritage Act 1972).

3 There are no doubt levels of generalisation at which one might speak of an Aboriginal culture, but in pre-invasion Australia there were many distinct Aboriginal groups, and thereafter dispossession, contact with different aspects of Western society, education, opportunity and many other pressures for cultural change and adaptation have operated, and continue to operate, differentially on groups and individuals.

4 Aboriginal Land Rights (Northern Territory) Act 1976 (Commonwealth), Aboriginal Sacred Sites Ordinance 1978, (Northern Territory). The former Act remains in force; the latter is superseded by the Northern Territory Aboriginal Sacred Sites Act 1989, which continues to use the same definition. Other examples of legislative broadening of the concept included 'sites and items of sacred, ceremonial, mythological or historic significance to the Aboriginal people', Aboriginal Heritage Act 1979 (South Australia), and places and objects 'which are or have been of sacred, ritual or spiritual or ceremonial significance to persons of Aboriginal descent' (Aboriginal Heritage Act 1972 (Western Australia).

5 'Aboriginal' is defined as 'a member of the Aboriginal race of Australia, and includes a descendant of the indigenous inhabitants of the Torres Strait Islands'.

6 Wootten, Hal 2003, 'Conflicting Imperatives: Pursuing Truth in the Courts' in I. McCalman and A. McGrath (eds) Proof and Truth, Academy of the Humanities, Canberra.

7 In October 1995, following unfortunate events in the Hindmarsh Island Bridge application, the then Labor Minister for Aboriginal and Torres Strait Islander Affairs asked Elizabeth Evatt AC to report on operation of the Act. In her Review of the Aboriginal and Torres Strait Islander Heritage Protection Act 1984 (August 1996) she made a number of recommendations to amend the Act. In December 1996, the Government having changed, the new Liberal Minister announced the Government's intention to make wide-ranging changes to the Act 'designed to prevent another Hindmarsh Island saga'. Very few of the Evatt recommendations were reflected in the government's subsequently issued proposals, which were considered by the Parliamentary Joint Committee on Native Title and the Aboriginal and Torres Strait Islander Land Fund, but remained contentious, and no legislation has resulted.

8 Lowitja O'Donohue described Senator Herron as 'a Minister without influence or purpose', The Australian 17 November 1997, p. 10.

${ }^{9}$ My recommended strategy was not adopted. Instead, as I have already noted, opposition was deflected by applying $\$ 5$ million of funds allotted for Aboriginal heritage protection to provide an alternative site for the waterskiers. 